Meta

Journal des traducteurs

Translators' Journal

\title{
Word Processing and the Translation Process - The Effect of the Medium on the Message
}

\section{Hildegund Bühler}

Volume 35, numéro 1, mars 1990

Actes du colloque international « La traduction proligère "

URI : https://id.erudit.org/iderudit/002178ar

DOI : https://doi.org/10.7202/002178ar

Aller au sommaire du numéro

Éditeur(s)

Les Presses de l'Université de Montréal

ISSN

0026-0452 (imprimé)

1492-1421 (numérique)

Découvrir la revue

Citer cet article

Bühler, H. (1990). Word Processing and the Translation Process - The Effect of the Medium on the Message. Meta, 35(1), 31-36.

https://doi.org/10.7202/002178ar d'utilisation que vous pouvez consulter en ligne. 


\section{WORD PROCESSING AND \\ THE TRANSLATION PROCESS - \\ THE EFFECT OF THE MEDIUM \\ ON THE MESSAGE}

HILDEGUND BÜHLER

Universität Wien, Vienna, Austria

For a long time in the history of mankind the only medium of expression in language was sound; only comparatively recently has writing become another kind of expression. Studies contrasting orality and literacy have of late become a focus of interest in linguistics (cf. e.g. Halliday 1986) as well as in translation studies (cf. e.g. GarciaLanda 1985, Bühler 1988a).

In our days as a consequence of modern technology the distinction between speech and writing is becoming blurred: working with the computer as a writing device, socalled word processing, which I prefer to call text processing (cf. the German Textverarbeitung), has become a third medium of linguistic representation within the oral-literate continuum.

When using the computer as a text-processing device, there are basic differences from the acoustic as well as from the graphic system of representation, drawing several qualities from each, but in their sum opening up a new dimension (cf. e.g. Schanze/ Kammer 1986). While in speaking the sound is evanescent and in writing the letters on paper are fixed, in producing a text directly on screen the typographic information is temporary and transient much like the acoustic sign, but it can also be stored temporarily or permanently by the system and eventually printed out and fixed on paper.

In text processing text is primarily a process, and only optionally becomes a product. Likewise translating defines itself as a process and a translation only becomes a finished product after a series of complicated and not yet fully explored mental operations. I would therefore like to proceed by drawing a few parallels between the translation process and text processing and conclude by elaborating some possible effects of the new medium on the message, by pointing out some consequences of text processing for translating, for translational behavior, hence for translation teaching and also for translation research.

If we define translating as an intelligent linguistic behavior, a communicative event, the mediation between languages and cultures, an interlinguistic and transcultural transfer, the translation process is a complex, multi-dimensional phenomenon, influenced and modified by a large number of situational factors.

Wolfram Wilss has suggested that the mental mechanisms which are related to translational performance - source text decoding, transfer and target text encoding are part of the mental make-up of mankind and will be observable in all cultures (Wilss $1989 \mathrm{~b}$ ). But in fact we know little about a person's mental performance in a particular translation situation and only occasionally do professional translators share their experience. 
This was done recently by Laura Gran (1989:9 8) who very vividly describes the process that seems to be generally valid for the interlingual transfer of messages. She claims that there are two distinct ways of simultaneous interpreting and that each approach is accompanied by a clear and specific feeling of what is happening. In the first approach you grasp the meaning of the speech and follow the logical flow of ideas. Here the message undergoes semantic analysis and is then rapidly re-coded into the target language. The interpreter feels detached from the lexical and syntactic patterns of the source speech and is able to maintain a considerable décalage. A sudden disturbing factor (e.g. a long series of figures, an unexpected change in tone (!) or content) occasionally obliges the interpreter to get closer to the surface structure of the original speech, to follow each segment of speech as it is delivered. Once you fall into this mot-à-mot pattern, whose outcome is poorer and less effective, according to Gran, a very special effort is needed to resume the former detached attitude. She maintains that one and the same interpreter in the course of interpreting a text will inevitably shift from one pattern to the other according to internal and external circumstances. As an outcome of the interdisciplinary research carried out at the University of Trieste (where she teaches), she furthermore offers an interesting hypothesis, a neurophysiological explanation for the different types of mental processes involved, based on the different skills ascribed to the two cerebral hemispheres. The left hemisphere might be more involved in the literal form of interpretation, while the right hemisphere might be more involved in the freer, meaning-guided pattern.

In a process-oriented typology of translation I have found it useful for didactic purposes to differentiate in a heuristic way between three basic types of mental text production in translating (cf. Bühler 1988b).

Type 1, which resembles the word-for-word pattern described above, can be described as a more or less mechanical process that involves lexical substitution on the langue level, in written translation occasionally calling for optional syntactic paraphrasing to meet target-language constraints. This translation process, which frequently entails a loss in information content and a change in text function, is rarely found in professional translation today, where most of the time no straightforward direct transfer is possible and where adaptive strategies are called for to compensate for interlingual and intercultural differences.

It occurs in human translational behavior mainly when translators stay within the realm of interlingually standardized text configurations (cf. the concept of fertigkeitsorientiertes Übersetzen in Wilss 1989 a). This will be the case for instance in routine special-language translation: by using your computer as a memory device, it will relieve your memory by storing terminology or text passages temporarily or permanently and by offering the possibility of fast retrieval of such stored data. Thus when translating directly on-screen with a data-base link-up, one will not only work with stored material in the form of standardized terminological equivalents, but also with repeatedly appearing prestructured paragraphs and phrases, kept on file and inserted when needed. One may introduce standardized text modules, standard formulations, and in certain translational situations one may even combine such stored text segments and produce merged documents. Such translational procedures are still in the experimental stage, but will probably be available before long (cf. also Varantola 1988).

Type 1 is however standard procedure in machine translation, where text processing comes in for post-editing on-screen. Here not only terminology, but also syntactic structures have to be corrected, and translators will post-edit machine output directly onscreen using structurally based macros that address particular language-pair-dependent syntactic constructions (cf. Vasconcellos 1986, Vasconcellos 1987). 
Type 2 and Type 3 are goal-directed activities to ensure information transfer and basically consist of a decoding and an encoding phase, a dichotomy that can be substituted by comprehension/reconstruction or even deverbalization/reverbalization (cf. also Wilss 1989b).

Type 2, which for didactic purposes I distinguish in a heuristic way from Type 3, consists not only of a phase of comprehending the source text and of restructuring the target text, but also of a transfer phase, which might be part of the encoding phase and is therefore not readily recognized by translators. I have, however, found it useful for students to make a conscious effort to recognize the processual components of this transfer/encoding phase. In addition to a context-sensitive substitution of larger text segments, various adaptive strategies are performed that are obligatory not only to satisfy target-language constraints, but also for shaping the target text to meet various communicative goals, e.g. functional equivalence between source text and target text or adaptation to the target-group culture. These procedures involve syntactic, semantic and pragmatic paraphrasing, adaptive strategies that can be speeded up and facilitated considerably by writing your text with the computer and using the various relevant functions provided by the software, such as delete, insert, search and replace, move, shift, copy.

Type 3 corresponds roughly to Gran's meaning-based approach. Here the translation process resembles a three-phase model, including not only a phase of analysis and a phase of restructuring, but also a nonverbal intermediary phase (sometimes called interlingua), which is believed to leave supposedly non-linguistic memory traces, from which a new target text is created. When translating with a computer as a text-processing device, it can be assumed that when your eyes are fixed on the screen it is easier to abstract from the original text and disregard its surface structure: you tend to be hypnotized not by the source text, but by the screen.

The professional profile of translators and interpreters today (cf. Bühler 1987) calls for flexiblity, for a translator who can handle mixed types and pursue all three modes of transfer as described above even within one single occurrence, depending on the communicative situation. This flexibility will be supported by the computer used as a textprocessing device.

Furthermore, translating must also be discussed within the framework of global vs. local information processing, since in translating obviously global and linear processes are overlapping.

Not only has Laura Gran described the two different types of mental processes experienced by the professional interpreter, but also Hans Krings (1988), in his experiment with the professional translator verbalizing the translation process (for professional translating as opposed to translational behaviour in the foreign-language classroom; $\mathrm{cf}$. also Bühler 1987), has also shown that his test person proceeds through a text not only in a linear but rather in a concentric way, - moving repeatedly back and forth through an entire text consisting of 18 sentences. Even more convincingly Frank Königs (1989), in comparing the verbalization of the translation process with videotapes of the test person, was able to observe that, while one problem was being solved locally by verbalization, the fingers of the test person already pointed to another part of the text, indicating that obviously part of her mental energy was absorbed elsewhere.

In our own typology, while Type 1 apparently follows a linear progression by substituting translational units, Type 2 and Type 3 are clearly textual activities. In defining translating as such a textual activity (in Bühler 1984), I gave a detailed description of the alternating stages of global comprehension of the source text, sequential transfer of minimal translation units, and global verification of the target text as to equivalence and/or adequacy with the source text. 
Clashes between these stages of global comprehension and verification and the linear presentation and production of the source text and the target text do not only constitute a problem in simultaneous interpreting, but are also felt acutely in the slow and tedious process of writing a translation by hand. As we shall show below, in processing your text with your computer you can overcome this handicap by combining local and global approaches when writing your translation.

Text processing and the translation process seem to have at least three things in common: they are both characterized by being temporary, tentative and fluid.

As regards fluidity, given full keyboard proficiency (which will be a matter of course in the forthcoming generation of translators), in working on-screen your translation can be produced quickly and effortlessly. In a rapid production of the target text that resembles oral translation, you can follow the cohesive thread of your thought, as you do not have to think about the end of a line or page: with automatic word wrap and automatic pagination you simply keep on typing, producing an endlessly moving text (cf. the German Fließtext). Text processing and translating are both also tentative and temporary.

The translation process is characterized by discontinuous text production, by false starts, repetitions, parenthetic remarks, which in translating with a computer as a textprocessing device you can delete or remedy easily. In translating directly on-screen you can make tentative notes and jot down your ideas freely, using incomplete utterances that can be expanded, combined, corrected at a later moment. Since, as we have already heard, translators more often do not work in linear sequence, when writing with the computer you can work at random, leaving gaps that can easily be filled later on: the text is expanded automatically when the insert function is used.

Moreover, as every translation goes through several stages of drafting, working onscreen also serves this temporary aspect. After you have gained skill in cursor positioning, you can move easily and speedily through the entire text and perform local or global changes. When translating with the computer as a writing device you can even survey the global textual consequences of changing one part and can speed up the process by using automatic search and replace functions.

We now have to ask ourselves what will be the consequences of this new medium of graphic representation for translating, and whether translating directly on-screen might possibly influence translational behavior?

The advantages of working directly on-screen are obvious.

Working with a computer not only facilitates routine tasks, like spelling checks, word division, harmonization of terminology, formatting and layout, but may above all enhance your ability to formulate and introduce new stylistic variations. You can modify your text easily and speedily by deleting, replacing, moving, or copying words, sentences, paragraphs, or entire sections.

Hence also your readiness to correct and revise is greatly enhanced. In the replace mode you type new text over existing text. Words can be replaced globally or selectively and by making use of search, delete and replace functions, which can also be carried out automatically throughout the text, corrections are entered more quickly. In short in writing your translation with a computer you always work with clean copy.

If we agree with Wolfram Wilss (Wilss 1989b) that today speed is a criterion for efficient translational behavior, when using a computer as a writing device the inevitable trade-off between quality and speed experienced in everyday professional situations will be biased in favor of higher quality. The translator's processing capacity will be effectively enhanced, especially in complex translational behavior. You will develop a fluent writing technique, your writing will be more spontaneous, the carrying out of your writing intention will be speeded up considerably. Also the use of macros, a sequence of 
functions that have been programmed as one function by the translator to deal with recurrent language-pair-specific situations, will help to simplify and speed up operations.

I will not go here into the obvious advantages of using your computer as an electronic dictionary that supplies LSP terminology by the insertion of such terminology in a link-up with a terminological data-base, since such procedures are already widely discussed in the relevant literature.

The potential disadvantages to be expected when writing with a computer can be mainly attributed to the difference between written and spoken language.

Written language follows close-knit syntactic structures and develops an elaborate and fixed grammar, while speech tends to be more loosely structured, showing a higher degree of redundancy and less semantic density per information unit (cf. Halliday 1986). If in working with a computer you follow this pattern of orality, your translation might be more readable, but you might also produce longer translations that are more loosely structured. And while translating by using a computer as a writing device might be more enjoyable, more relaxing, and while the production of a target text might be requiring less effort, this might be detrimental to your criticial judgement as to its intrinsic qualities.

In order to set off these potential negative aspects, special editing skills will be required. They will above all have to be attended to in translation teaching, where we will have to think about incorporating these new writing skills in our curriculum, by teaching our students a combination of mechanical, linguistic, and pragmatic techniques. We should not only provide information about the PC and its software, but also about the basic operations of mental text-production in translating as they can be supported by the various functions, about the techniques to be employed in the revision, correction and adaptation of texts and in the storing and retrieval of information.

As regards possible applications of the new medium in research into the translation process, translation scholars so far in implementing psycholinguistic approaches have tried to discover what goes on in the translators' heads by making them verbalize translational procedures in the so-called thinking-aloud method (cf. e.g. Krings 1988). As an alternative I have recently suggested to supplement this approach by making students report in writing on their translational strategies as part of their routine translation assignments, a procedure which I have used successfully for a number of years and which yields autodiagnostic and autotherapeutic effects (Bühler 1990 forthcoming). But using a computer as a writing device might lend itself to yet another research project: viz. examining the various stages of the translation process by studying all the previous modifications of the final target text in the consecutive draft translations stored in the computer.

In summing up we might say that text processing by means of a computer more than any other previous writing device influences our ability to formulate and memorize. It seems that writing directly on-screen, which resembles speech in many ways, frees the translation process from various pragmatic constraints and returns to the thought the freedom of creative re-organization and re-adaptation. Since what the computer can do for us largely depends on the available software, further improvement can be expected.

\section{BIBLIOGRAPHY}

BÜHLER, H. (1984) : "Textlinguistische Aspekte der Übersetzungsdidaktik". Wilss, W., Thome, G. (eds.) Die Theorie des Übersetzens und ihr Aufschlusswert für die Übersetzungs - und Dolmetschdidaktik, Tübingen, G. Narr, pp. 250-260.

BÜHLER, H. (1987): "Language and Translation: Translating and Interpreting as a Profession", Kaplan, R. (ed.) Language and the Professions. Annual Review of Applied Linguistics, 7, Cambridge, Cambridge University Press, pp. 105-119.

BÜHLER, H. (1988a): "Oral Translation: Translating the Spoken Text", Bozini, V., Marzolini, M. (eds.) Linguistica e traduzione. Atti del Seminario di Studi, Premeno (Novara), Villa Bernocchi, 25-27 settembre 1987, Comune di Milano: Scuola Superiore per Interpreti e Traduttori, pp. 1-23. 
BÜHLER, H (1988b) : “Übersetzungstyp und Übersetzungsprozeduren bei sogenannten Fachtexten”, Arntz, R. (ed.) Textlinguistik und Fachsprache. Akten des Internationalen übersetzungswissenschaftlichen AILASymposions Hildesheim 13-16 April 1987, Hildesheim, Zurich, New York, Olms, pp. 281-297.

BÜHLER, H. (1990): "Didaktische Aspekte des literarischen Übersetzens", Der Deutschunterricht 1./1990 (forthcoming).

GARCIA-LANDA, M (1985) : "Les relations interprète / traducteur au niveau théorique", Bühler, H. (ed.) Der Übersetzer und seine Stellung in der Öffentlichkeit. Translators and their Position in Society. Le traducteur et sa place dans la société. Xth World Congress of FIT. Proceedings, Wien, Braumüller, pp. 187-190.

GRAN, L. (1989): "Interdisciplinary Research on Cerebral Assymetries: Prospects for the Teaching of Interpretation", GRAN, L., DODDS, J. (eds.) The Theoretical and Practical Aspects of Teaching Conference Interpretation, Udine, Campanotto Editore, pp. 93-100.

HALLIDAY, M. A. K. (1986) : Spoken and Written Language, Victoria, Deakin University Press.

KÖNIGS, F. (1989): "Vom Kopf in den Mund? Anmerkungen zum Übersetzungsprozeß und dessen Erforschung", Studien zum polnisch-deutsch Sprachvergleich 3, Zeszyty Naukowe Uniwersytetu Jagiellonskiego.

KRINGS, H.P. (1988): "Blick in die 'Black Box' - Eine Fallstudie zum Übersetzungsprozess bei Berufsübersetzem", Arntz, R. (ed.) Textlinguistik und Fachsprache. Akten des Internationalen übersetzungswissenschaftichen AlLA-Symposions Hildesheim 13-16 April 1987, Hildesheim, Zürich, New York, Olms pp. 393-413.

SCHANZE, H. and KAMMER, M. (1986) : Textverarbeitung. Eine Einführung. Grundlagen und Anwendungen, München, Fink

VARANTOLA, K. (1988): "Term Banks, Text Banks and Bank Users", Proceedings, Nordisk Datalinguistikdage og Symposium for datmatstottet leksikografi og terminologi 1987, Handelshojskolen i Kobenhavn, pp. 301-312.

VASCONCELLOS, M. (1986) : "Functional Considerations in the Postediting of Machine-Translated Output. Dealing with V(S)O vs. SVO", Computers and Translation 1.1, pp. 21_38.

VASCONCELLOS, M. (1987) : Postediting on-screen: Machine Translation from Spanish into English (Ms.).

WILSS, W. (1989a) : "Was ist fertigkeitsorientiertes Übersetzen?", Lebende Sprachen, 3/89, pp. 105-113.

WILSS, W. (1989b) : Towards a multi-facet concept of translation behavior (Ms.). 